\title{
Electron Beam Modification on Dielectric, Thermal, and Thermo-mechanical Properties of Styrene Butadiene Rubber/Clay Nanocomposites
}

\author{
M.M. Atta ${ }^{1}$, A.S. El-Bayoumi ${ }^{1 *}$, M.Madani ${ }^{3}$, G.M. Nasr ${ }^{2}$ and S. Hamza ${ }^{2}$ \\ (1) Radiation Physics Department, National Center for Radiation Research and Technology (NCRRT), Egyptian Atomic Energy \\ Authority (EAEA), Cairo, Egypt. \\ (2) Physics Department, Faculty of Science, Cairo University, Cairo, Egypt. \\ (3) Physics Departmen,. College of Science and Humanities in Jubail, Imam Abdurrahman Bin Faisal University, Saudi Arabia.
}

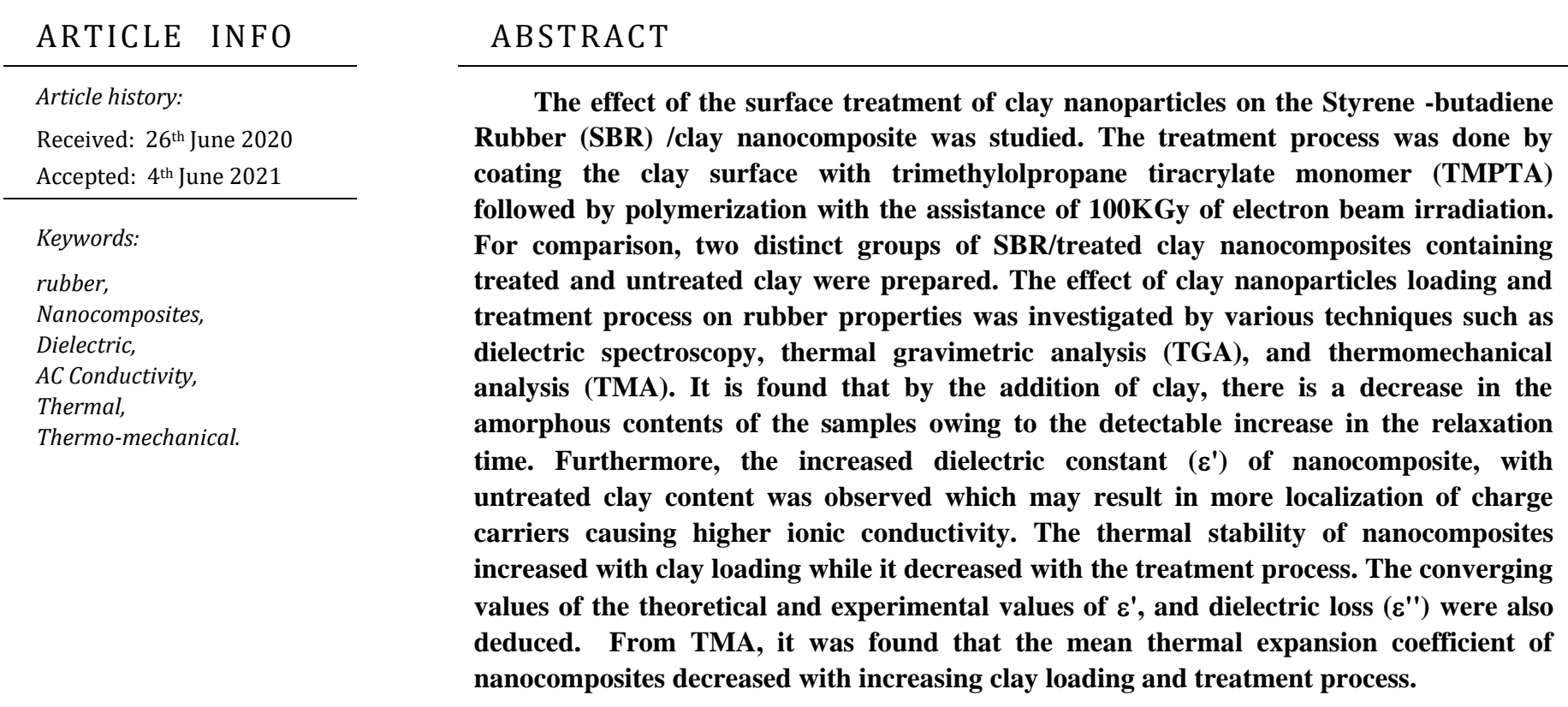

\section{1- INTRODUCTION}

Polymer nanocomposites have attracted attention because of the improved physical properties of matrix polymer caused by nanofillers. Amongst nanocomposites, those based on layered silicate and clay have been extensively investigated because of the clay abundance availability, low cost, and intercalation [1, 2]. For many years, clay was extensively used as a filler and is of great commercial interest to produce cheap products. Compared to pristine polymers, polymer -clay nanocomposite exhibited enhanced fire-retardant, increased thermal stability, reduced gas permeability, and increased mechanical properties[3].

Unfortunately, the clay drawback is its low reinforcing ability caused by its low surface activity compared to other fillers such as carbon black. Thus, the surface modification of filler became progressively important to improve the adhesion to the polymers matrix. The surface coating of fillers can be conducted via some coupling agents or filler surface coating with some monomer, followed by polymerization of the monomer. For example, the reinforcing ability of clay was improved through its surface coating by silane coupling agents $[4,5]$. In addition, the surface treatment of clay filler with an acrylate monomer, trimethylolpropane triacrylate monomer (TMPTA) followed by electron beam irradiation, has been reported. The surface-treated clay showed better physical properties when incorporated into nitrile rubber compared to untreated clay[6].

In the present work, the intercalated clay filler was treated via surface coating with trimethylolpropane triacrylate monomer (TMPTA) polymerized by electron beam irradiation. The effects of clay treatment process 
on the dielectric, thermal, and thermo-mechanical properties of styrene-butadiene rubber (SBR)-Clay nanocomposite studied. For this purpose, two groups of styrene-butadiene rubber SBR /Clay nanocomposite were prepared with different loading from both treated and untreated Clay fillers. The enhanced physical properties of nanocomposites were observed upon clay loading.

\section{2- EXPERIMENTAL WORK}

\subsection{Materials}

Styrene-butadiene rubber (SBR-1502, styrene content-23.5\%) was supplied by Synthetic and Chemicals Ltd, Barielley, India .The clay nanopowder (bentonite, BE125, mean size $100 \mathrm{~nm}$, density $=2.5 \mathrm{gcm}^{-3}$ ) was obtained from Spectrum Chemicals\& Laboratory Products, USA. The acrylate monomer, trimethylolpropane triacrylate (TMPTA: flash point $>1000 \mathrm{C}$, b.p. $>1000 \mathrm{C}$, specific gravity $1110 \mathrm{~kg} / \mathrm{m}^{3}$ ) was obtained from UCB chemicals, Belgium. TMPTA was used as a grafting monomer without further purification.

\subsection{Radiation pre-grafting of clay}

Clay nanoparticles were heated at $120^{\circ} \mathrm{C}$ for about $5 \mathrm{hrs}$ to eliminate the absorbed water. Then, 100 grams of the clay was mixed with $100 \mathrm{ml}$ of TMPTA in acetone under constant stirring for about $10 \mathrm{~min}$. The solvent was then removed by evaporation and fillers were grinded to obtain a surface coated powder. The treated filler was then irradiated by $1.5 \mathrm{MeV}$ electron beam accelerator (ICT Model), Egyptian Atomic Energy Authority. The beam power over the whole energy range was $37.5 \mathrm{KW}$, the average energy current was $12.5 \mathrm{~mA}$, and the total absorbed dose was $100 \mathrm{KGy}$. The FWT 60-00 dosimeter, calibrated by CERIC/CEROUS dosimeter, was used to determine the absorbed dose for treated filler. The uncertainty in the absorbed dose was estimated to be $1.15 \%$ [7].

The atomic composition of samples was examined by JEOL-JSM 5800 scanning microscope equipped with a Linux X-ray analyzer (EDX). The samples were sputter-coated by a thin layer of gold ready for scans and measurements. The sputtering process occurred at $30 \mathrm{~mA}$ for $30 \mathrm{sec}$. For comparison, the untreated clay was also irradiated with $100 \mathrm{KGy}$ of the electron beam. The atomic concentrations of different clays individual elements are presented in Table (1). There is no observed change in the untreated clay sample upon irradiation. In contrast, a noticeable decrease in the oxygen element ratios in the treated sample, compared to the untreated one, indicates the presence of acrylate on the treated clay surface [8].
Table (1): EDX results for clay nanofillers

\begin{tabular}{cccc}
\hline \multirow{2}{*}{ sample } & \multicolumn{2}{c}{ Atomic concentration (\%) } & O/elements (\%) \\
\cline { 2 - 3 } & oxygen & elements & \\
\hline Untreated Clay & 47.68 & 52.32 & 0.91 \\
$\begin{array}{c}\text { Irradiated untreated } \\
\text { clay (100 kGy) }\end{array}$ & 47.68 & 52.32 & 0.91 \\
Treated clay & 46.60 & 53.40 & 0.87 \\
\hline
\end{tabular}

\subsection{Preparation of SBR-Clay Nanocomposite}

For comparison, untreated and treated clay fillers were incorporated in SBR rubber in different concentrations $(0,5,10,15,20$, and $30 \%)$. The produced nanocomposites were designated according to clay ratios in the polymer matrix as shown in Table (2) for untreated clay and Table (3) for treated clay. To prepare nanocomposite, SBR rubber was mixed in a Brabender Plasticorder PLE-319 at $80 \mathrm{rpm}$ for 2 minutes at $80^{\circ} \mathrm{C}$. Then the compound ingredients were added to SBR with different ratios as shown in Tables $(2,3)$. The total time of mixing was 10 minutes. After compounding, the stocks were left for $24 \mathrm{hrs}$ to mature. Then they were cured into sheets of $2 \mathrm{~mm}$ thick using a hot press at $5 \mathrm{MPa}$ pressure in an electrically heated press (type carver M-154) and heating temperature $170 \pm 2^{\circ} \mathrm{C}$ for 20 mins.

Table (2): The formulation of SBR-untreated clay nanocomposites

\begin{tabular}{l|c|c|c|c|c|c}
\hline \multirow{2}{*}{ Ingredient ratio (\%) } & \multicolumn{7}{|c}{ Samples } \\
\cline { 2 - 7 } SBank & Su5 & Su10 & Su15 & Su20 & Su30 \\
\hline Zinc oxide & 100 & 100 & 100 & 100 & 100 & 100 \\
\hline Stearic acid & 5 & 5 & 5 & 5 & 5 & 5 \\
\hline Clay & 2 & 2 & 2 & 2 & 2 & 2 \\
DCP & 0 & 5 & 10 & 15 & 20 & 30 \\
\hline Sulphur & 1 & 1 & 1 & 1 & 1 & 1 \\
\hline & 2 & 2 & 2 & 2 & 2 & 2 \\
\hline
\end{tabular}

Table (3): The formulation of SBR-treated clay nanocomposites

\begin{tabular}{l|c|c|c|c|c}
\hline \multirow{2}{*}{ Ingredient ratio (\%) } & \multicolumn{5}{|c}{ Samples } \\
\cline { 2 - 6 } & St5 & St10 & St15 & St20 & St30 \\
\hline SBR & 100 & 100 & 100 & 100 & 100 \\
Zinc oxide & 5 & 5 & 5 & 5 & 5 \\
\hline Stearic acid & 2 & 2 & 2 & 2 & 2 \\
\hline Clay & 5 & 10 & 15 & 20 & 30 \\
DCP & 1 & 1 & 1 & 1 & 1 \\
\hline Sulphur & 2 & 2 & 2 & 2 & 2 \\
\hline
\end{tabular}




\subsection{Characterization techniques}

TMA analysis was carried out at an expansion mode using Shimadzu TMA-50 thermomechanical analyzer. Polymer samples (length $15 \mathrm{~mm}$ ) were heated from ambient temperature to $120^{\circ} \mathrm{C}$ at a heating rate of $\left(10^{\circ} \mathrm{C} / \mathrm{min}\right)$. Thermogravimetric analysis was carried out using Shimadzu TGA-50 thermo- gravimetric analyzer. The samples were heated from 25 to $600^{\circ} \mathrm{C}$ at a rate of $10^{\circ} \mathrm{C}$ $\mathrm{min}^{-1}$ under nitrogen atmosphere. The dielectric properties were measured using a bridge (Hioki 3532-50 LCR Hi Tester) in the frequency (f) range of $10^{2}-10^{6} \mathrm{~Hz}$. The prepared samples were in the form of disks of $0.2-0.3 \mathrm{~cm}$ thick and $1.0 \mathrm{~cm}$ in diameter. The dielectric constant $\varepsilon^{\prime}$ (real part of the dielectric constant) of the samples and the ac conductivity ( $\sigma$ ac) were calculated by using the relations

$$
\begin{aligned}
& \varepsilon^{\prime}=\frac{\mathrm{d}}{\varepsilon_{\mathrm{o}} \mathrm{A}} \mathrm{C} \\
& \sigma_{\mathrm{ac}}=\omega \varepsilon_{\mathrm{o}} \varepsilon^{\prime \prime} \\
& \varepsilon^{\prime \prime}=\varepsilon^{\prime} \tan \delta
\end{aligned}
$$

Where $\mathrm{C}$ is the capacitance of the sample, $\mathrm{d}$ is the thickness of the sample, $\mathrm{A}$ is the cross-sectional area of each of the parallel surfaces of the sample, $\varepsilon 0$ is the permittivity of free space, $\varepsilon "$ is the dielectric loss, and $\omega$ is the angular frequency $(\omega=2 \pi \mathrm{f})$.

\section{RESULTS AND DISCUSSION}

\subsection{Dielectric Analysis}

The dielectric relaxation spectroscopy (DRS) was used to examine the molecular mobility in SBR-clay nanocomposites. In addition to the investigation of dipolar processes, special attention is paid here to the analysis of conductivity effects as a tool for studying interface properties.

Fig.(1) compares the variation of the relative dielectric constant as a function of frequency for SBR matrix with different clay concentrations (treated and untreated) at room temperature. In all cases, strong frequency dispersion of permittivity was observed in all frequency range.

A step-permittivity at around $10^{5} \mathrm{~Hz}$ is observed. The decrease of $\varepsilon^{\prime}$ with an increase in frequency may be attributed to electrical relaxation processes, but at the same time, the material electrode polarization cannot be ignored. There is a detectable effect of clay (both treated and untreated) on the value of $\varepsilon^{\prime}$ for all the frequency range. The untreated clay may result in more localization of charge carriers along with mobile ions causing higher ionic conductivity. This may be the reason for higher $\varepsilon^{\prime}$ and strong low-frequency dispersion $[9,10]$.

Fig.(2) shows the variation of dielectric loss with frequency for two SBR matrix groups with different clay ratios at room temperatures. The loss spectra consist of two peaks at characteristic frequencies for both nanocomposites groups which recommend the existence of dipoles in all samples. The strength and frequency of relaxation depend on the characteristic property of dipolar relaxation. It is observed that the peak frequency (the first peak) shifted towards the lower frequency side with the increase in clay concentration. As the peak shifts towards the lower frequency side, the relaxation time is increased. By the clay addition, it is believed that there is a decrease in the amorphous content of the sample.
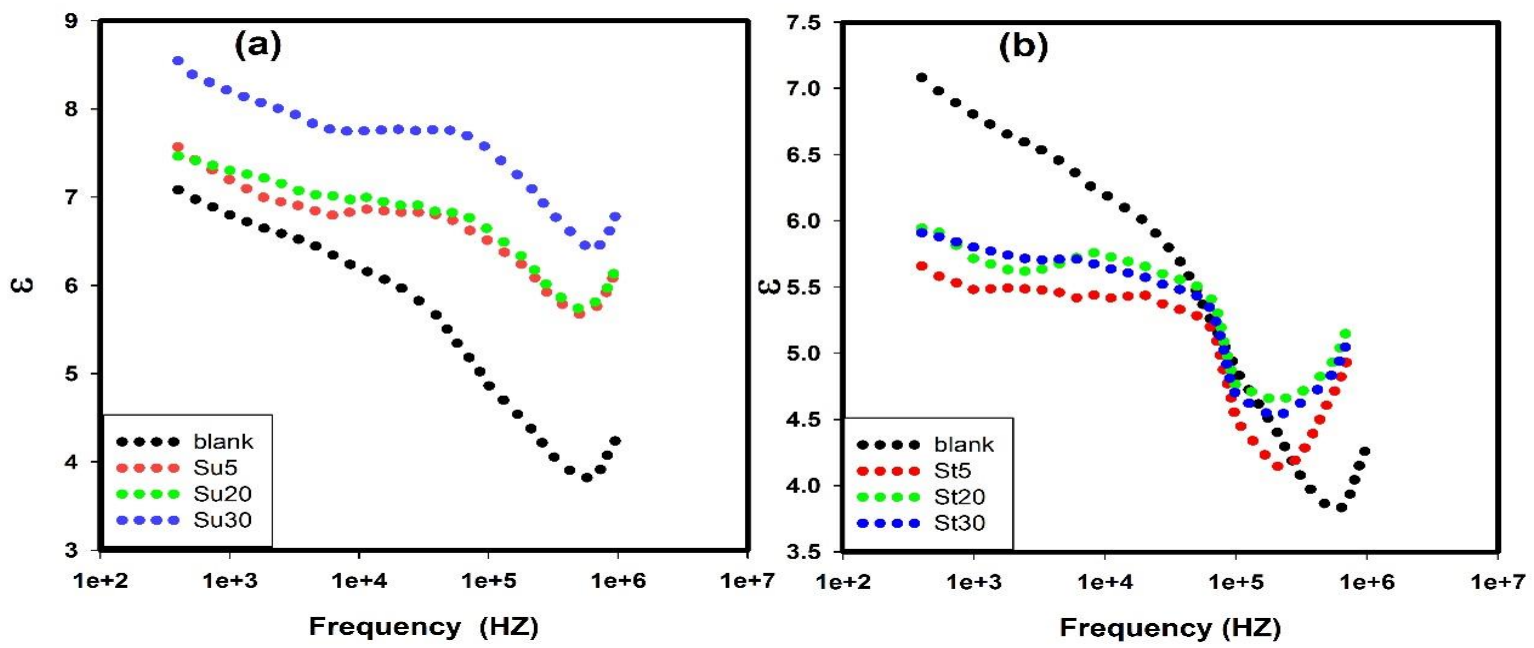

Fig (1): Dielectric constant as a function of frequency for nanocomposite filled with a) untreated and b) treated clay 

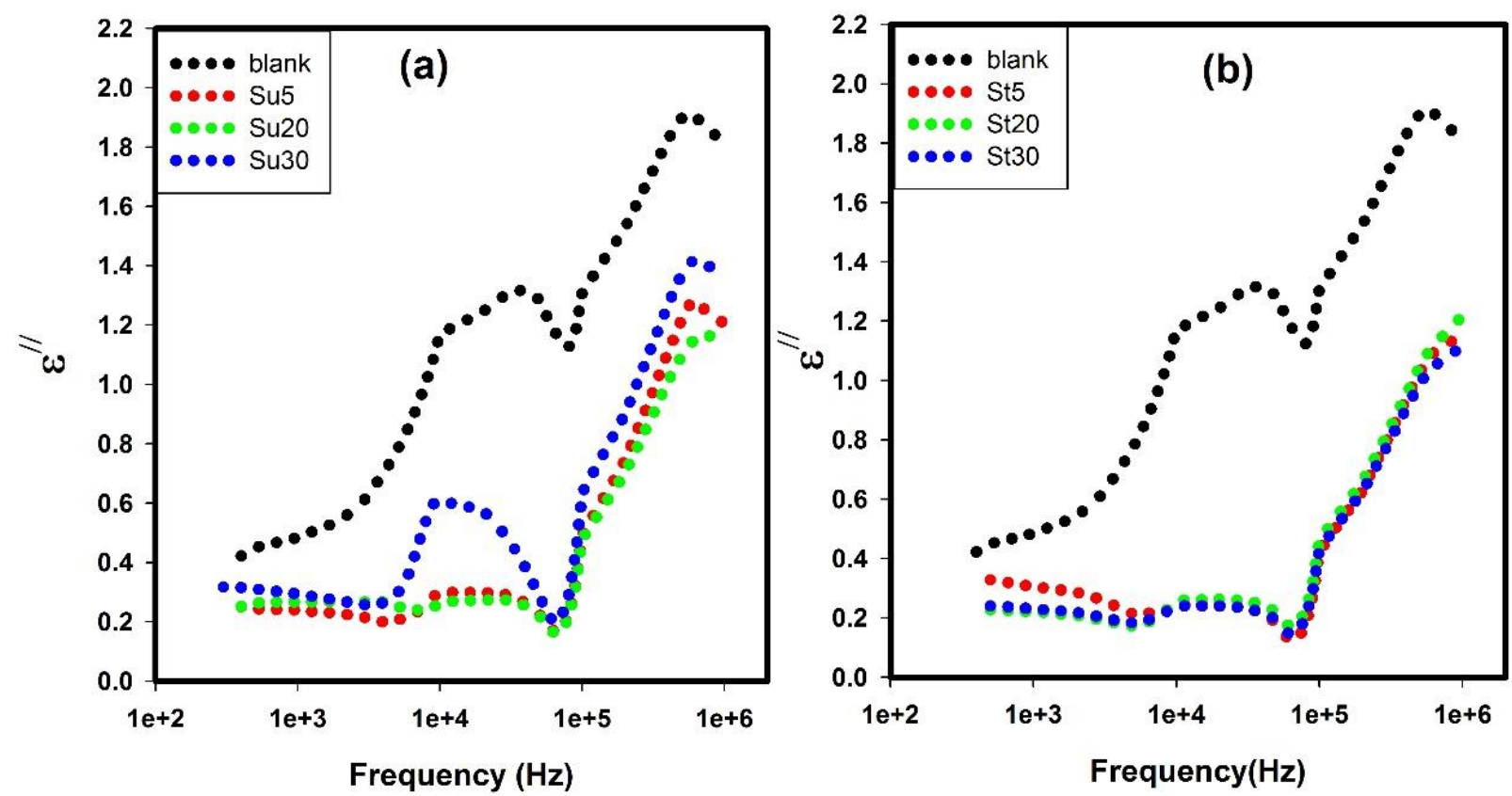

Fig. (2): Dielectric loss as a function of frequency for nanocomposites filled with a) untreated and b) treated clay
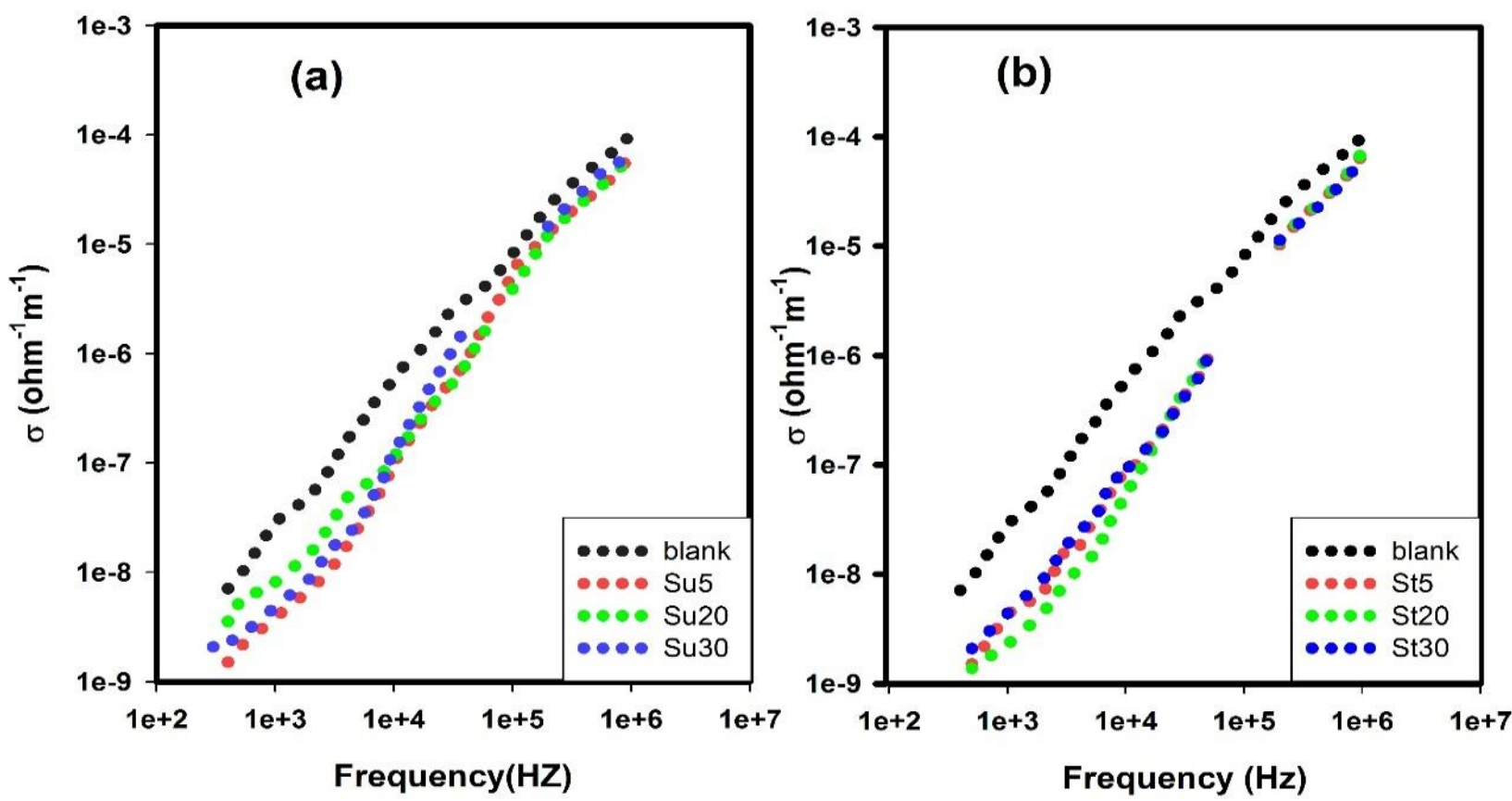

Fig. (3): Ac conductivity versus frequency for nanocomposites filled with a) untreated and b) treated clay

The plots of Ac conductivity $\left(\sigma_{A c}\right)$ vs. frequency at room temperature showed a similar behavior for all samples, as shown in Fig.3. This illustrates that $\sigma_{\mathrm{Ac}}$ is frequency-dependent. Moreover, the phenomena of increasing conductivity with increasing frequency may be interpreted by the hopping conduction [11]. Moreover, the linear dependence of $\sigma_{\mathrm{Ac}}$ with frequency could explain the electronic conduction via the hopping process [12]. 


\subsection{Volume fraction dependence}

The proposed equation of Tsangaris et al [13] was tested in our samples. A comparison between the experimental and theoretical values $\varepsilon^{\prime}$ and $\varepsilon^{\prime \prime}$ was made. Tsangaris et al. [13] equations express the dielectric permittivity $\varepsilon^{\prime}$, and dielectric loss $\varepsilon^{\prime \prime}$ of composite material in terms of applied field frequency and the component characteristics as equations (4) and (5).

$\varepsilon_{\text {eff }}^{\prime}=\left[\frac{\varepsilon^{\prime}}{\left[\left(\varepsilon^{\prime}-1\right)^{y}+1\right.}\right]\left\{\left[\left(\frac{\sigma_{A c}}{\omega \varepsilon_{0}}\right)^{1 / 2}\left(\varepsilon^{\prime}-1\right)^{1-v_{2}} \cos \left(\frac{\pi v_{2}}{2}\right)^{y}+1\right]\right\}$

$\varepsilon^{\prime \prime}{ }_{e f f}=\varepsilon^{\prime \prime}\left\{\left[\left(\frac{\sigma_{A c}}{\omega \varepsilon_{0}}\right)^{v_{2}-1}\left(\varepsilon^{\prime}-1\right)^{1-v_{2}} \sin \left(\frac{\pi v_{2}}{2}\right)^{y}+1\right]\right\}$

Where, $y$ is the depolarizing factor [14], which depends on the aspect ratio and orientation of the fillers [15] given by equation (6) [16]:

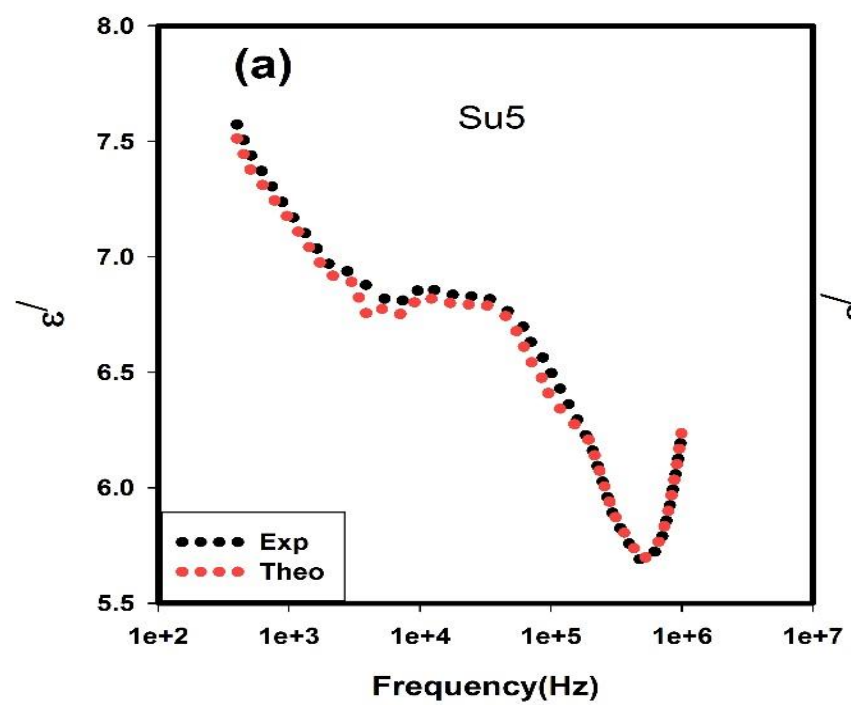

$$
y=\frac{1}{1-(a / b)^{2}}-\frac{a / b}{\left[1-(a / b)^{2}\right]^{3 / 2}} \cos ^{-1}(a / b)
$$

Where $a / b$ is the aspect ratio of the fillers and $v_{2}$ the volume fraction of the filler.

For all samples, the theoretical value of real $\varepsilon^{\prime}$ and imaginary $\varepsilon^{\prime \prime}$ part of the dielectric permittivity is calculated by application equations (4) \& (5). As shown in Fig. (4) an approach between the experimental value and theoretical model can be observed. Essentially, the shape of clay particles may be transformed from spherical to ellipsoidal or even to a long rod shape according to the volume fraction of filler. Besides, the value of depolarizing factors decreased by the increase of the clay content in the SBR matrix as shown in Table (4). This indicates that the clay particles or aggregates turn from the shape of oblate ellipsoids with the minor axes (a) parallel to the applied frequency to the shape of the sphere.

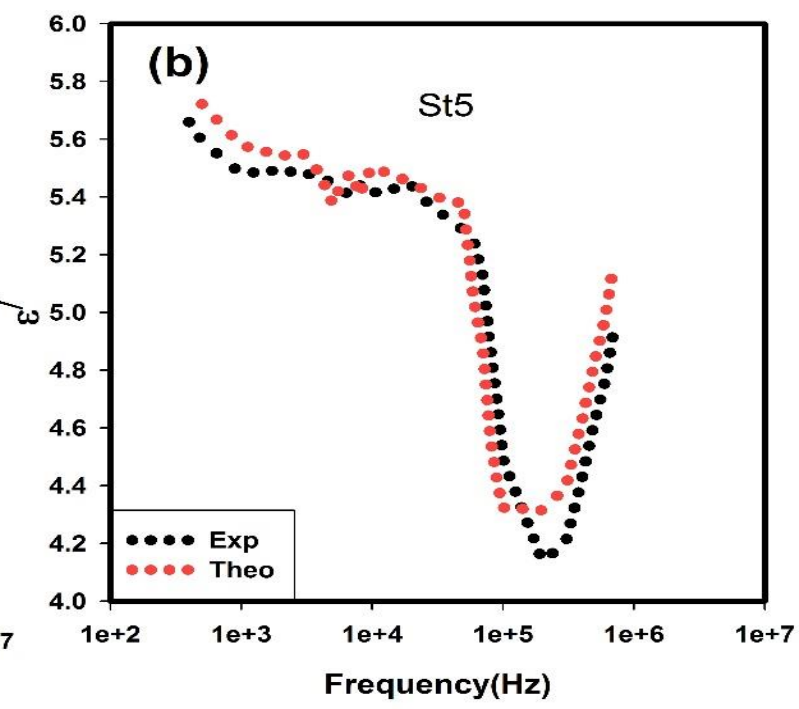

Fig. (4): The experimental and theoretical relation between dielectric constant and the frequency for a) sample su5, and b) for sample st5

Table (4): The values of depolarizing factor (Y) chosen to fit the calculated $\varepsilon$ 'eff with the experimental data for all samples

\begin{tabular}{|c|c|c|}
\hline Clay content (phr) & Untreated sample & Treated sample \\
\hline zero & \multicolumn{2}{|c|}{0.1} \\
\hline 5 & 0.4 & 0.09 \\
\hline 20 & 0.36 & 0.05 \\
\hline 30 & 0.09 & 0.025 \\
\hline
\end{tabular}




\subsection{Thermogravimetric Analysis (TGA)}

In many critical applications, the thermal stability of polymeric compounds is required for application suitability. Thermogravimetric analysis (TGA) is one of the most important techniques to study the thermal stability of materials. The TGA data can also be used in studying the kinetics of decomposition, which provides an insight on the thermal stability of polymeric materials[17-19].

The TGA curves of the nanocomposites filled with untreated and treated clay are given in Fig.(5). The results of the thermograms are given in Tables (5). It is evident from the thermograms that nanocomposites are thermally stable up to $200^{\circ} \mathrm{C}$. As previously pointed out [17], the presence of a volatile matter, e.g. stearic acid, and the by-products of vulcanization causes the initial minor weight loss at around 190- $200{ }^{\circ} \mathrm{C}$. Furthermore, the presence of unreacted compounding ingredients in the blank sample and weak links in the skeleton of the macromolecules may cause early degradation [20].
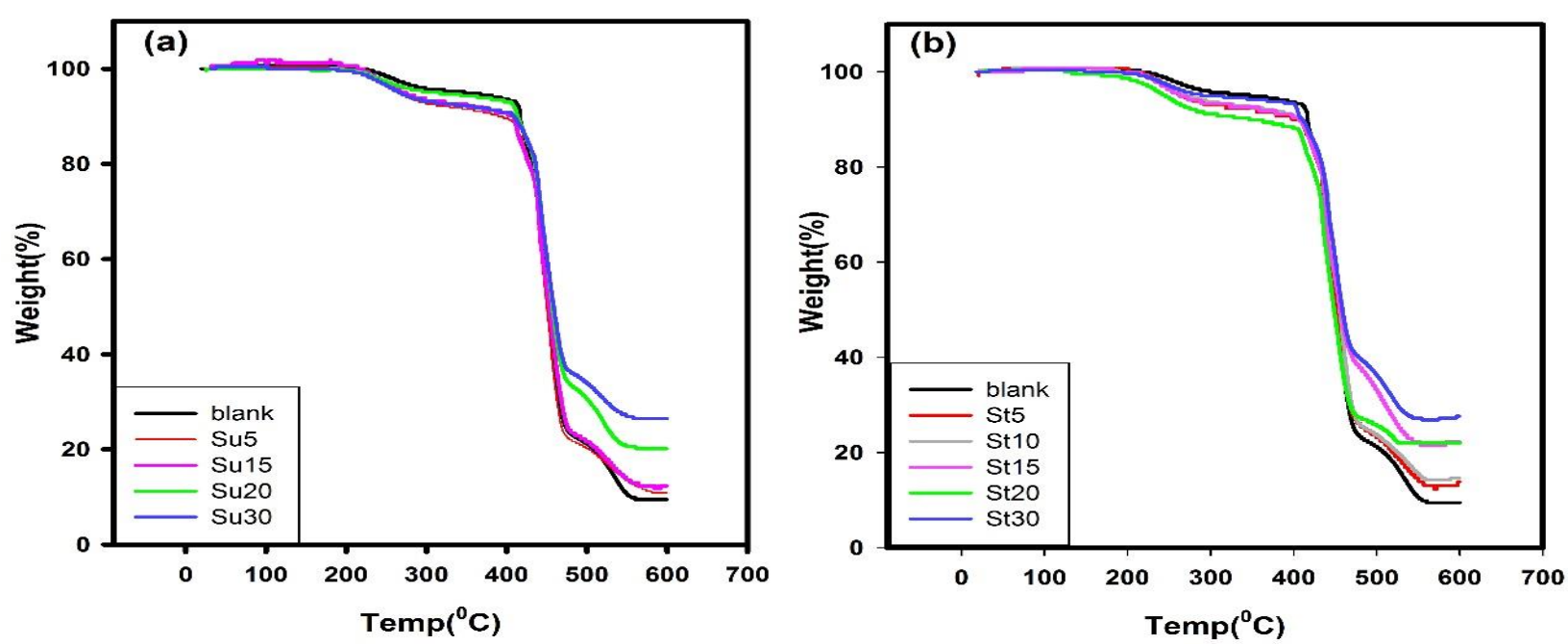

Fig. (5): TGA Thermograms of nanocomposites filled with a) untreated and b) treated clay samples.

Table (5): TGA results for untreated and treated clay samples

\begin{tabular}{cccccc}
\hline Sample & $\begin{array}{c}\text { Onset } \\
\mathbf{T e m p}^{\mathbf{0}} \mathbf{C}\end{array}$ & $\begin{array}{c}\text { Chair residue at } \\
\mathbf{6 0 0}^{\mathbf{0}} \mathbf{C}(\boldsymbol{\%})\end{array}$ & $\mathbf{T d}^{\mathbf{0}} \mathbf{C}$ & $\begin{array}{c}\text { Activation energy } \\
\left(\mathbf{j ~ k}^{-\mathbf{1}} \mathbf{~ m o l}^{\mathbf{1}}\right)\end{array}$ & $\begin{array}{c}\text { Weight loss in the major } \\
\text { degradation step (\%) }\end{array}$ \\
\hline Blank & 410 & 9.486 & 420 & 75.81 & 48.2 \\
Su5 & 409 & 10.82 & 409.5 & 88.483 & 63.8 \\
Su15 & 435 & 12.34 & 435.8 & 82.652 & 41.4 \\
Su20 & 410 & 20.16 & 410 & 71.37 & 55.5 \\
Su30 & 392 & 26.48 & 392 & 85.95 & 49.8 \\
St5 & 410 & 13.84 & 410 & 86.478 & 56.1 \\
St10 & 417 & 14.644 & 417.5 & 91.23 & 58.6 \\
St15 & 433 & 22.2 & 433.8 & 56.46 & 33.4 \\
St20 & 407 & 22.02 & 407.2 & 82.5 & 40.6 \\
St30 & 400 & 27.626 & 400.6 & 76.63 & 47.5 \\
\hline
\end{tabular}


As shown in Table (5), the presence of untreated and treated clay nanoparticles with different ratios in the SBR composites highly affects the weight loss in the major degradation step compared to that of the blank sample. From thermogram analysis, it is concluded that the nanocomposites degradation is mainly controlled by the filler type and concentration.

The thermal stability was further confirmed by determining the activation energy (Ea) for the thermal decomposition of all composites according to Horowitz and Metzger method [21]. Equation (7) is used for the calculation of Ea as follows:

$$
\ln \ln \left(\frac{w_{o}}{w t}\right)=\frac{E_{a \theta}}{R T_{s}^{2}}
$$

In this method, a plot of $\ln \left\{\ln \left[\left(\mathrm{W}_{0^{-}} \mathrm{W}_{\mathrm{f}}\right) /\left(\mathrm{W}_{\mathrm{t}^{-}} \mathrm{W}_{\mathrm{f}}\right)\right]\right\}$ against $\theta$ gives a straight line with a slope of $\left(\mathrm{Ea} \times 10^{3}\right) / \mathrm{R} T_{s}^{2}$, in which the activation energy can be calculated from the slope (Fig.6).

Where, $\mathrm{W}_{0}$ and $\mathrm{W}_{\mathrm{f}}$ are the initial and final weights of samples, respectively. $\mathrm{W}_{\mathrm{t}}$ is the weight of the sample at time $t$ and $\theta=T-T_{s}, T$ is the temperature of the sample,
$\mathrm{T}_{\mathrm{s}}$ is the reference temperature defined as the temperature where $\left[\left(\mathrm{W}_{\mathrm{t}^{-}} \mathrm{W}_{\mathrm{f}}\right) /\left(\mathrm{W}_{0}-\mathrm{W}_{\mathrm{f}}\right)\right]=1 / \mathrm{e}$, where $\mathrm{R}$ is the gas constant $\left(\mathrm{R}=8.314 \mathrm{~J} \mathrm{~K}^{-1} \mathrm{~mol}^{-1}\right)$.

The calculated activation energies for all samples are given in Table (5).

It can be concluded that the activation energy decreases with the treatment process while it increased with an increase in the clay loading. Meanwhile, the weight loss has an undulatory behavior with both clay loading and treatment process.

\subsection{Thermomechanical analysis (TMA)}

Thermomechanical analysis (TMA) is referring to the method capable of measuring the thermal expansion coefficient of materials in its most refined form, but it is sometimes used simply to determine the location of the glass transition temperature [22].

Fig.(7) displays an example for all samples of the TMA expansion curves for all treated and untreated clay-loaded SBR nanocomposites at an applied load of $15 \mathrm{~g}$.
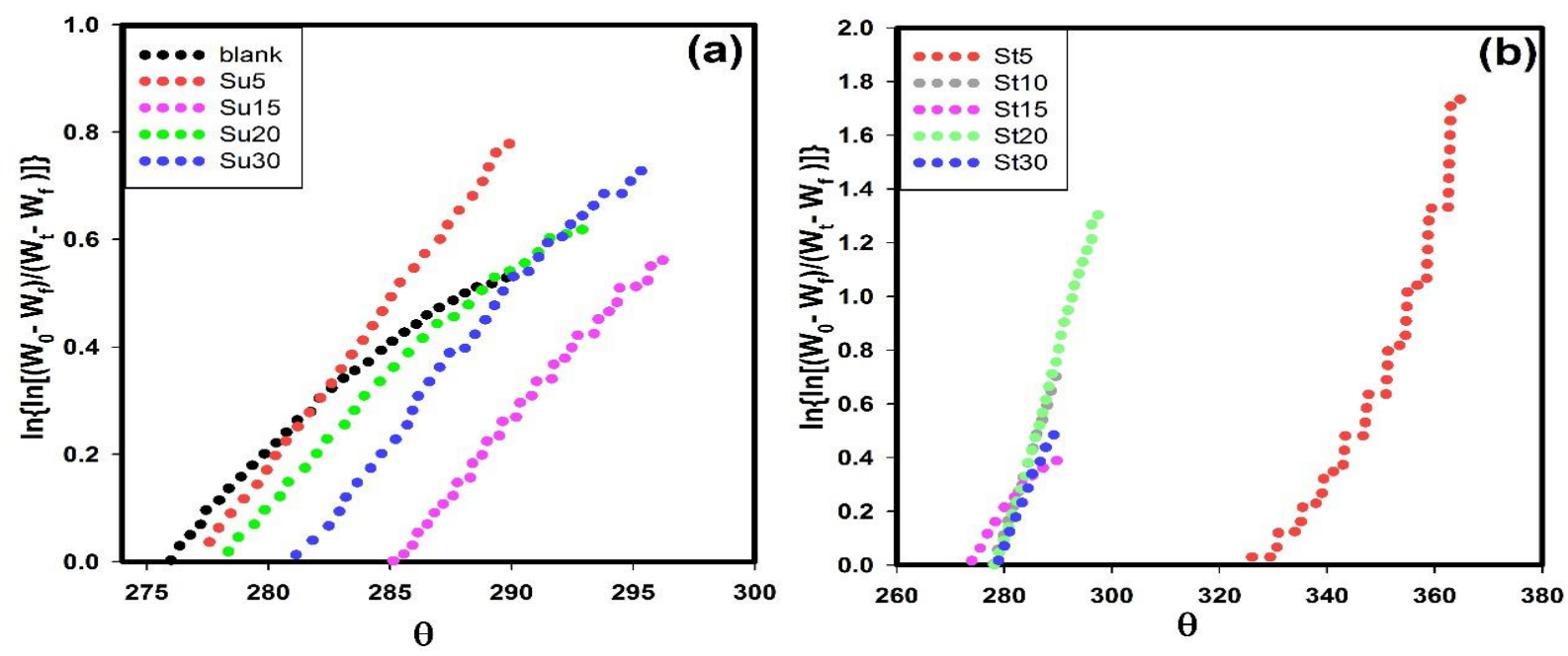

Fig. (6): Slope for nanocomposites filled with a) untreated, and b) for treated clay nanoparticles

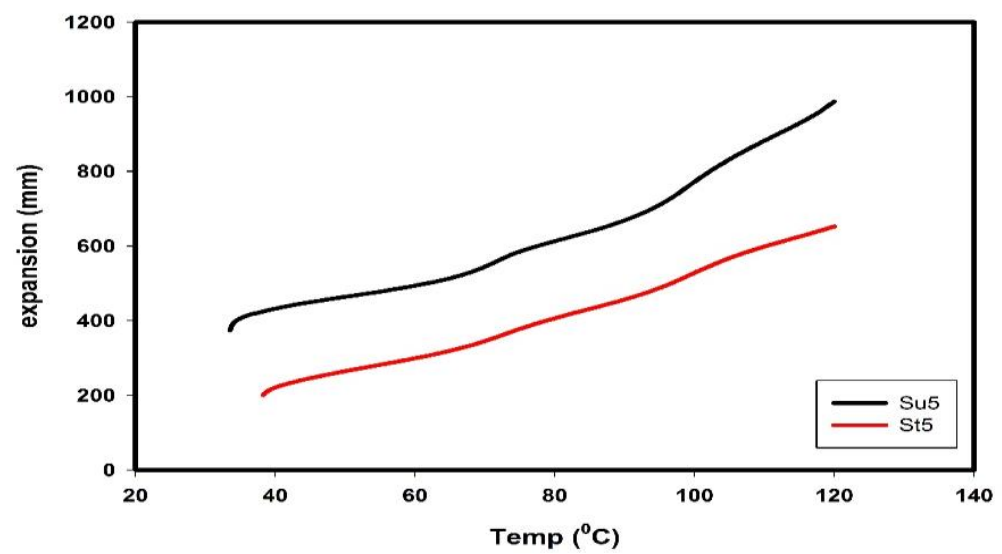

Fig. (7): TMA expansion curve for Su5 and St5 Sample 
The transition of the structure from the equilibrium liquid to the glassy state with a change in the temperature is observed experimentally from the changes in volume and linear expansion. Below some temperature, the structure relaxation is completely arrested on the experimental time scale, and the glassy state is reached. This transition is shown in Fig.(7) and also all samples by TMA expansion curves of clay loaded rubber. The glassy state is characterized by the glass line, i.e, the linear dependence of expansion on temperature found at relatively lower temperatures. It clears from Fig.(7) that the transition region depends on the clay contents for treated and untreated cases. The observed departure of expansion from equilibrium liquid values is mainly due to the glass transition temperature of polystyrene contents in the SBR loaded samples.

The temperature at which the departure of expansion occurs and the intersection of the equilibrium line with the glass line extrapolated to lower temperatures varies from $90{ }^{\circ} \mathrm{C}$ at zero clay loading decreased to $84^{\circ} \mathrm{C}$ at $5 \mathrm{phr}$ clay loading.

The mean coefficient of thermal expansion (CTE), $\alpha$ $=(\Delta \mathrm{L}) 10^{6} / \mathrm{L}_{\mathrm{O}}(\Delta \mathrm{T})$ where $\Delta \mathrm{L}$ is the change in length of samples in the direction being measured, $\mathrm{L}_{\mathrm{O}}$ is the initial length of the sample, and $\Delta \mathrm{T}$ is the change in temperature calculated over specified regions of expansion curves for all samples. The mean CTE values are plotted against clay loading for both nanocomposite groups as shown in Fig. (8). A slightly lower $\alpha$ is found with increasing clay loading (especially for treated one). The transition region, defined here by the temperature span between the limiting equilibrium and glassy lines, is found to diminish significantly with increasing clay loading. This transition arises when the molecular mobility greatly increases in the specimen as a result of heating [23].

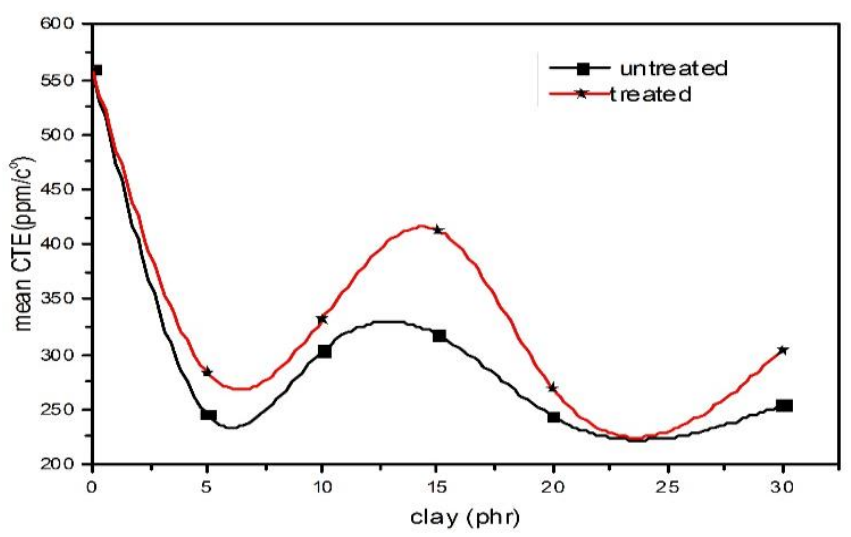

Fig. (8): Mean CTE with clay content (phr) for nanocomposites filled with treated and untreated clay

\section{CONCLUSION}

Treated and untreated clay fillers were used to prepare clay /SBR nanocomposites using an internal mixture. By the addition of clay, it is believed, that there is a decrease in the amorphous contents of the nanocomposites owing to the detectable increase in the relaxation time as observed from the DRS measurements.

The depolarizing factor, calculated by Tasangaris equation indicates the change of the shape of clay particles from oblate ellipsoids to the spherical shape with the applied frequency. It was found that the addition of untreated and treated clay nanoparticles highly affects the weight loss in the major degradation step of unfilled composite. In addition, composite degradation was mainly controlled by the filler type and concentration where thermal stability decrement of treated claypolymer nanocomposites was observed. Moreover, the thermal stability was further confirmed by determining the activation energy (Ea) for the thermal decomposition of all composites according to Horowitz and Metzger method. The transition region between the limiting equilibrium and the glassy lines is found to diminish significantly with increasing clay loading as deduced from the thermo-mechanical curves. The transition region is also found to diminish significantly with increasing clay loading. This transition arises when molecular mobility greatly increases in the specimen as a result of heating.

\section{REFERENCES}

[1] Shioyama, H., 1997. Polymerization of isoprene and styrene in the interlayer spacing of graphite. Carbon (New York, NY), 35(10-11), pp.1664-1665.

[2] Hernan, L., Morales, J., Sanchez, L., Santos, J. and Castellón, E.R., 2000. Sol-gel derived Li-V-Mn-O spinels as cathodes for rechargeable lithium batteries. Solid State Ionics, 133(3-4), pp.179-188

[3] Fornes, T.D., Yoon, P.J., Keskkula, H. and Paul, D.R., 2001. Nylon 6 nanocomposites: the effect of matrix molecular weight. Polymer, 42(25), pp.0992909940

[4] shida, H. and Miller, J.D., 1984. Substrate effects on the chemisorbed and physisorbed layers of methacryl silane-modified particulate minerals. Macromolecules, 17(9), pp.1659-1666

[5] De la Orden, M.U., Arranz, J., Lorenzo, V., Pérez, E. and Urreaga, J.M., 2010. Study of the effects of the reaction conditions on the modification of clays 
with polyelectrolytes and silanes. Journal of colloid and interface science, 342(1), pp.185-191

[6] Ray, S. and Bhowmick, A.K., 2002. Electron-beammodified surface-coated clay: influence on mechanical, dynamic mechanical and rheological properties of ethylene-octene copolymer. Radiation Physics and Chemistry, 65(3), pp.259-267

[7] Fried, J.R. and Radhuber, N., 2003. Polymer Science and Technology, 2 nd.

[8] Treloar, L.R.G., 1975. The physics of rubber elasticity. Oxford University Press, USA)

[9] Baskaran, R., Selvasekarapandian, S., Hirankumar, G. and Bhuvaneswari, M.S., 2004. Vibrational, ac impedance and dielectric spectroscopic studies of poly (vinylacetate)-N, N-dimethylformamideLiClO4 polymer gel electrolytes. Journal of Power sources, 134(2), pp.235-240.

[10] Schönhals, A. and Kremer, F., 2003. Analysis of dielectric spectra. In Broadband dielectric spectroscopy (pp. 59-98). Springer, Berlin, Heidelberg

[11]Lee, C., Lee, S., Sul, C. and Bae, S., 1997. Frequency dependence of AC conductivities of KNb1- $x V x O 3$ single crystals. Physica B: Condensed Matter, 239(3-4), pp.316-321

[12] Rao, R.V. and Shridhar, M.H., 2002. Effect of Ptoluene sulphonic acid on the dielectric properties of poly (4-vinylpyridine). Materials Science and Engineering: A, 325(1-2), pp.73-78.

[13] Tsangaris G., Psarras G., Kouloumbi N., (1996),Journal of Materials science and technology. 12,533
[14] Hedvig, P., 1977. Dielectric spectroscopy of polymers. Wiley.

[15] Vogel F.L., (1977) Journal of Materials Science. 12,982

[16] Tsangaris, G.M., Psarras, G.C. and Kontopoulos, A.J., 1991. Dielectric permittivity and loss of an aluminum-filled epoxy resin. Journal of noncrystalline solids, 131, pp.1164-1168

[17] Madani, M., 2008. Mol. Phys.: An International Journal at the Interface Between Chemistry and Physics 106, 849

[18] Madani, M., 2010. Structure, optical and thermal decomposition characters of LDPE graft copolymers synthesized by gamma irradiation. Bulletin of Materials Science, 33(1), pp.65-73.

[19] Mequanint, K., Sanderson, R. , Pasch, H., 2002. Polymer degradation and stability. 77,121.

[20] Deuri, A.S. and Bhowmick, A.K., 1986. Ageing of rocket insulator compound based on EPDM. Polymer degradation and stability, 16(3), pp.221-239.

[21] Horowitz, H.H. and Metzger, G., 1963. A new analysis of thermogravimetric traces. Analytical chemistry, 35(10), pp.1464-1468

[22] Campbell, D., Pethrick, R.A. and White, J.R., 2000. Polymer characterization: physical techniques. CRC press.

[23] Mark, J., Ngai, K., Graessley, W., Mandelkern, L., Samulski, E., Wignall, G. and Koenig, J., 2004. Physical properties of polymers. Cambridge University Press. 